University of Nebraska - Lincoln

DigitalCommons@University of Nebraska-Lincoln

1975

\title{
The Prediction of Lake Huron Lake-Effect Snowfall Systems
}

Kenneth F. Dewey

Follow this and additional works at: https://digitalcommons.unl.edu/natrespapers

Part of the Natural Resources and Conservation Commons, Natural Resources Management and Policy Commons, and the Other Environmental Sciences Commons

This Article is brought to you for free and open access by the Natural Resources, School of at DigitalCommons@University of Nebraska - Lincoln. It has been accepted for inclusion in Papers in Natural Resources by an authorized administrator of DigitalCommons@University of Nebraska - Lincoln. 


\title{
The Prediction of Lake Huron Lake-Effect Snowfall Systems
}

\author{
KenNeth F. Dewey \\ Depl. of Geography, The University of Nebraska, Lincoln 68508
}

(Manuscript received 22 February 1974, in revised form 24 July 1974)

\begin{abstract}
Data were collected during the 1971-72 snowfall season for the Lake Huron basin. The bulk aerodynamic approach, as formulated by Priestley, was utilized to estimate the daily average flux of heat and moisture over the lake. It was hypothesized that discriminant analysis could be employed to determine the threshold value (discriminant index) of the energy flux which is necessary for the occurrence of the lake-effect snowfall system. To determine the validity of this threshold value, the discriminant index was applied to a series of historical data. The results of this analysis indicated that the discriminant index could be utilized to forecast lake-effect snowfall days.
\end{abstract}

\section{Introduction}

One of the significant climatic features of the Great Lakes region is the lake-effect snowstorm. Richards and Derco (1963) have indicated that roughly 50\% of the snowfall in the Great Lakes snowbelt areas can be attributed to lake-effect storms. The various snowbelts are illustrated in Fig. 1. Hourly falls of $5-8 \mathrm{~cm}$ and daily falls of $60-90 \mathrm{~cm}$ have been observed to the lee of the Great Lakes (Wiggin, 1950; Sykes, 1966). Snowfalls of this magnitude can severely cripple transportation and communications. The lake-effect snowfalls are also a water resource for the Great Lakes basin.

Lake-effect snowfall can be defined as snowfall resulting directly from the influence of a large inland body of fresh water. By definition, the snowfall occurring during lake-effect periods would not have developed were it not for the input of heat and moisture into the overlying atmosphere. Synoptically, the lake-effect system develops when cold arctic air passes over the relatively warmer body of water. The heat and moisture injected into the lower layers of the advected air mass act as the stimulus for the production of mesoscale convective processes. The response to this mesoscale convection is the initiation of the characteristic snow squalls or flurries.

\section{Theoretical considerations}

It is hypothesized that the turbulent flux of heat and moisture over the lake can be utilized as a unique discriminator for the occurrence of lake-effect snowfall days. It is assumed that there is a threshold value for this energy flux which is required for the production of clouds and precipitation.
Phillips (1972) found that using the bulk aerodynamic method, first formulated by Priestly (1959), the turbulent transfer of heat $(H)$ and moisture $(E)$ over a body of water could be estimated quite easily and with a high degree of accuracy. McVehil et al. (1969) also achieved a high degree of success with this technique. The equations utilized in this method take the form

$$
\begin{aligned}
& H=\rho c_{p} C_{D} U\left(T_{a w}-T_{w}\right), \\
& E=\rho C_{E} U\left(q_{s}-q_{a}\right),
\end{aligned}
$$

where $T_{a w}$ is the ambient air temperature $2 \frac{1}{2} \mathrm{~m}$ above the water surface, $T_{w}$ the surface water temperature, $q_{a}$ the specific humidity $2 \frac{1}{2} \mathrm{~m}$ above the water surface, $q_{s}$ the specific humidity of the air in contact with the water surface, $\rho$ the density of the air, $c_{p}$ the specific heat of the air at constant pressure, $U$ the wind speed at approximately $10 \mathrm{~m}$ above the water surface, and $C_{D}$ and $C_{E}$ the dimensionless drag and evaporative coefficients. The evaporative heat flux $(L E)$ takes into account the latent heat energy which is removed from the water surface during evaporation. Eq. (2) then takes the form

$$
L E=\rho C_{E} U L\left(q_{s}-q_{a}\right) .
$$

The vertical flux of energy $(\Delta Q)$ over the lake can be expressed as a combination of Eqs. (1) and (3):

$$
\Delta Q=(H+L E) .
$$

The area of open water will directly influence the magnitude of the energy flux. This is observed to the lee of Lake Erie and Georgian Bay, where lake-effect snowfall decreases in intensity and gradually disappears as the water bodies become ice covered. 


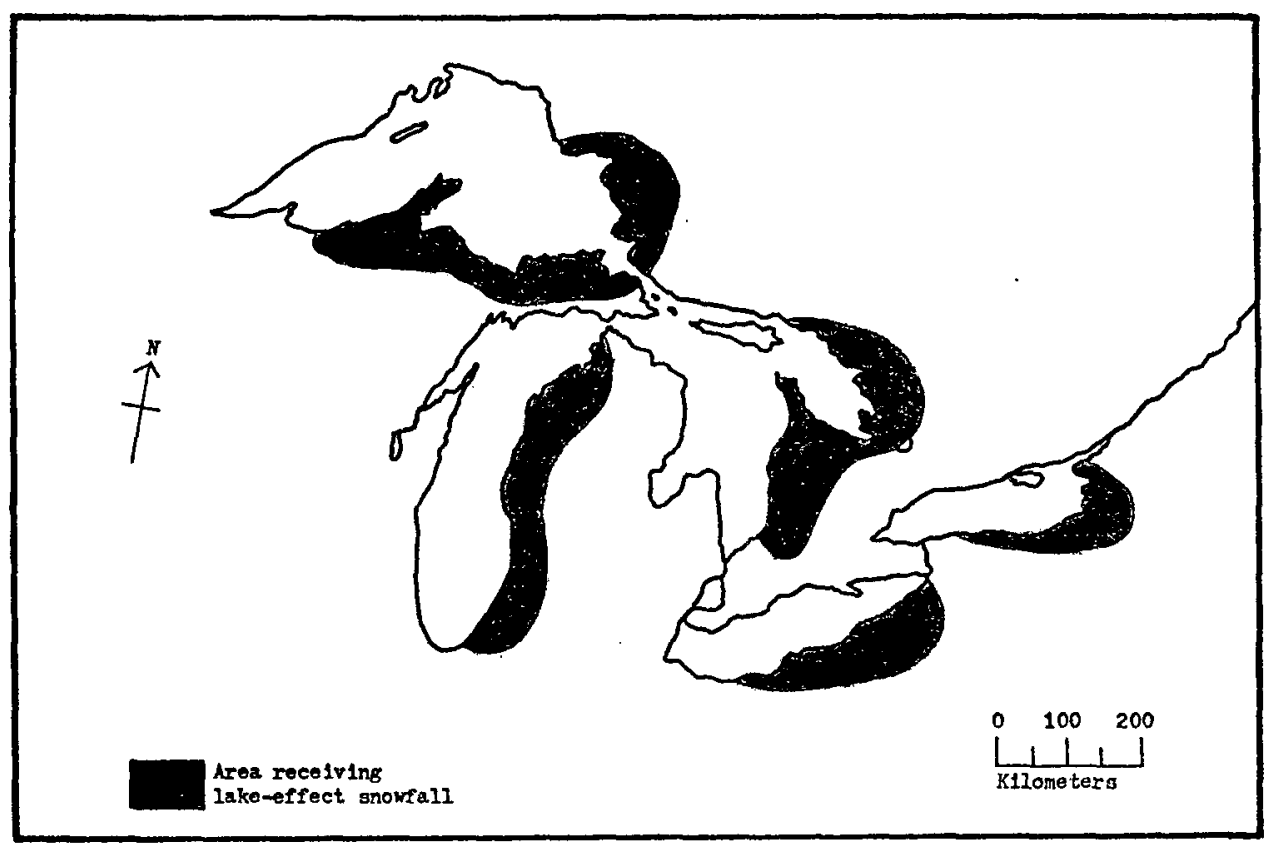

FIG. 1. Lake-effect snowbelts of the Great Lakes (after Eichenlaub, 1970).

Eq. (4) can be rewritten then as

$$
\Delta Q=(H+L E) A,
$$

'where $A$ is the area (percent) of open water for the mesoscale lake surface.

The major problem in the use of these equations is the accurate estimation of the meteorological parameters over the body of water. Richards $e t$ al. (1966) have produced a series of empirically derived land/lake wind ratios for various classifications of overland wind speed, atmospheric stability, and overwater fetch. Phillips (1972) developed a series of regression equations which can be utilized to determine the temperature and humidity gradient over a lake from land values.

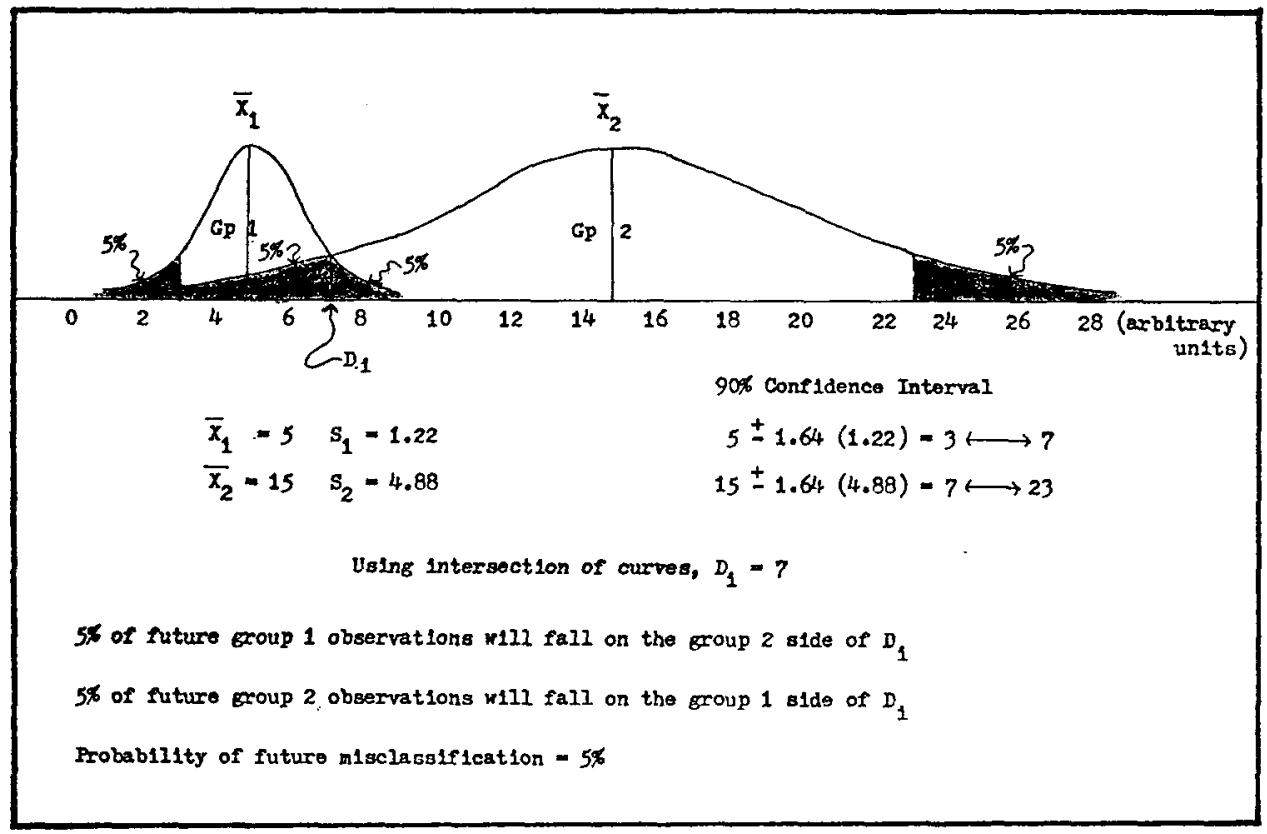

FIG. 2. Determination of the probability of misclassification. 


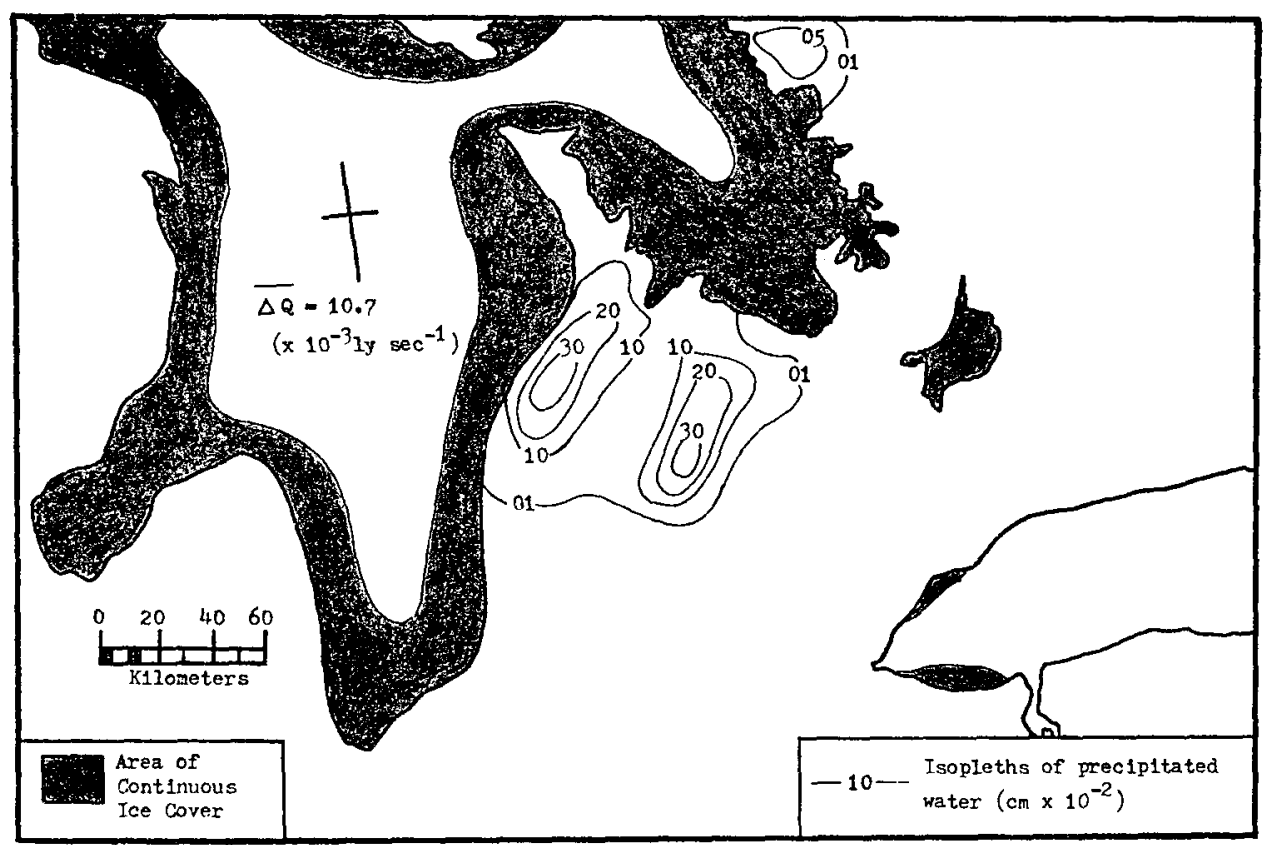

FIG. 3. Observed precipitation and ice cover for 10 February 1972.

\section{The development of a lake-effect index}

The prediction of occurrence of lake-effect snowfall lends itself well to discriminant analysis. When the observations are taken, it must be known to which class each observation belongs in order to conduct the discriminant analysis and develop a discriminant index. In this analysis, it is the problem of assignment of days to the classes lake-effect and non-lakeeffect. The discriminant index is a threshold value which can be utilized in future forecasting situations to predict the occurrence of lake-effect snowfall days. A simplified form of discriminant analysis can be employed to determine if discrimination is possible on the basis of the one parameter, the mean (for a $24 \mathrm{~h}$ period) vertical flux of energy over the lake $(\overline{\Delta Q})$. Fig. 2 illustrates the procedure involved in this statistical technique. After the standarized curves are drawn for the two populations, the probability of future misclassification using the threshold value (discriminant index $D_{i}$ ) can be calculated.

\section{Research methodology}

The Lake Huron basin was chosen for statistical purposes. Data were gathered during the 1971-72 snowfall season (November through March). The study period was further broken down into one-day intervals (0900-0900 EST). All days of frontal and cyclonic precipitation over the study region, as observed on the synoptic charts, were removed from the data sample. All days with average wind directions from $020^{\circ}$ to $200^{\circ}$ azimuth were omitted because with these wind directions, the study region was not downwind of Lake Huron. The Monthly Records of Meteorological Observations (Atmospheric Environment Service, 1971-72) were examined, as well as the radar reports from London and Toronto, Ontario, for the remaining 63 days which were not eliminated by the above test criteria. All days were then classified as either lake-effect (39 days) or non-lake-effect (24 days).

The vertical flux of energy along representative trajectories over Lake Huron was estimated using hourly upwind temperature and wind data in conjunction with Eqs. (1) and (3). The overwater air temperatures and dew points were generated using the regression equations which were developed in Phillips' (1972) study of air mass modification. Overwater winds were estimated using overland wind data and the statistical relationships outlined by Richards et al. (1966). A value of $2.3 \times 10^{-3}$ was adopted as the value for $C_{D}$ and $C_{E}$, based upon the success McVehil et al. (1969) had using this value.

The magnitudes of $H$ and $L E$ which were calculated for the various trajectories were spatially averaged and the mean flux of energy for the entire lake surface $(\Delta Q)$ was estimated using Eq. (5). The ice cover data necessary for Eq. (5) were obtained from charts prepared in Ottawa, Ontario, by Ice Central of the Atmospheric Environment Service. A $24 \mathrm{~h}$ average flux of energy $(\overline{\Delta Q})$ was calculated for each of the days in the study period. Fig. 3 shows the estimated mean vertical energy flux over the lake $(\overline{\Delta Q})$, the ice 


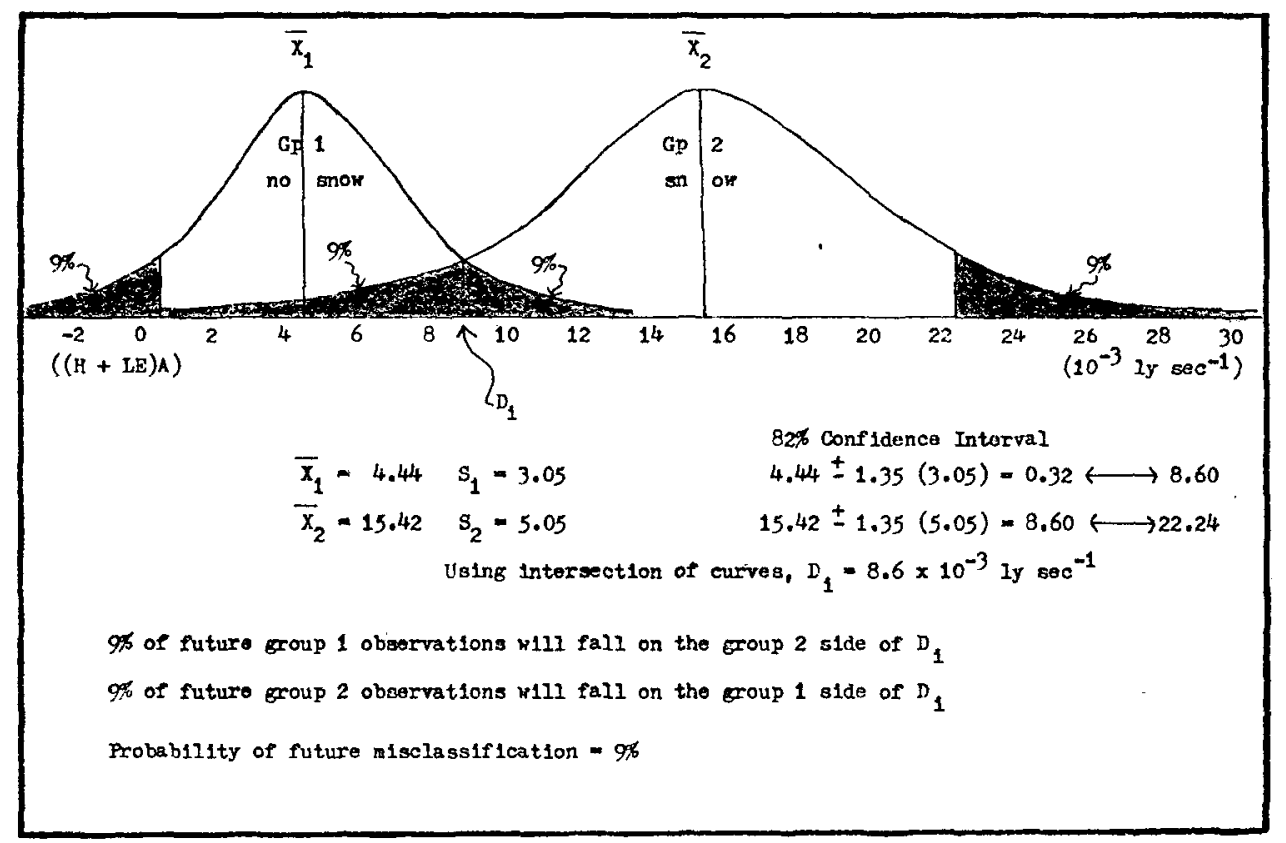

FIG. 4. Results of the 1971-72 lake-effect snowfall discriminant analysis.

cover, and the resulting precipitation for one of these lake-effect snowfall days.

\section{Analysis of the results}

Fig. 4 gives the results of the discriminant analysis. As indicated, the average energy flux over the lake must exceed $8.6 \times 10^{-3} \mathrm{ly} \mathrm{s}^{-1}$ for the occurrence of a lake-effect snowfall day. It can also be concluded, using this lake-effect index, that there is a $9 \%$ probability of misclassifying future days.

There were no temperature surveys of Lake HuronGeorgian Bay during the subsequent snowfall seasons

TABLE 1. 1969-70 test data for the prediction of occurrence.

\begin{tabular}{|c|c|c|c|c|c|c|}
\hline Date & $\begin{array}{c}A \\
(\%)\end{array}$ & $H+L E$ & $(H+L E) A$ & Prediction* & Observation & $\begin{array}{c}\text { Maximum } \\
\text { amount** } \\
\text { (cm precipitated } \\
\text { water) }\end{array}$ \\
\hline 6 Nov. & 100 & 1.5 & 1.5 & no snow & no snow & - \\
\hline 16 Nov. & 100 & 7.4 & 7.4 & no snow & no snow & $\overline{0}$ \\
\hline 21 Nov. & 100 & 13.1 & 13.1 & snow & snow & 2.03 \\
\hline $4 \mathrm{Dec}$ & 100 & 17.8 & 17.8 & snow & snow & 0.76 \\
\hline 5 Dec. & 100 & 4.3 & 4.3 & no snow & no snow & - \\
\hline 16 Dec. & 100 & 13.5 & 13.5 & snow & snow & 0.51 \\
\hline 17 Dec. & 100 & 8.9 & 8.9 & snow & snow & 0.64 \\
\hline $20 \mathrm{Dec}$. & 100 & 11.7 & 11.7 & snow & snow & 0.51 \\
\hline 27 Dec. & 98 & 11.0 & 10.8 & snow & snow & 0.25 \\
\hline 10 Jan. & 95 & 17.3 & 16.4 & snow & snow & 2.03 \\
\hline $13 \mathrm{Jan}$. & 93 & 21.8 & 20.3 & snow & snow & 3.05 \\
\hline 14 Jan. & 90 & 14.1 & 12.7 & snow & snow & 0.51 \\
\hline 18 Jan. & 90 & 16.8 & 15.1 & snow & snow & 1.65 \\
\hline 21 Jan. & 90 & 17.0 & 15.3 & snow & snow & 0.76 \\
\hline 30 Jan. & 80 & 12.0 & 9.6 & snow & snow & 1.52 \\
\hline $6 \mathrm{Feb}$. & 65 & 3.8 & 2.5 & no snow & no snow & - \\
\hline $7 \mathrm{Feb}$ & 6.5 & 5.8 & 3.8 & no snow & no snow & - \\
\hline 13 Feb. & 60 & 18.2 & 10.9 & snow & snow & 0.61 \\
\hline $16 \mathrm{Feb}$. & 60 & 10.4 & 6.2 & no snow & snow & 0.15 \\
\hline $20 \mathrm{Feb}$. & 55 & 14.2 & 7.8 & no snow & snow & 1.02 \\
\hline 28 Feb. & 55 & 7.1 & 3.9 & no snow & no snow & -- \\
\hline 5 Mar. & 55 & 1.5 & 0.8 & no snow & no snow & - \\
\hline 8 Mar. & 50 & 16.7 & 8.4 & no snow & snow & 0.64 \\
\hline 29 Mar. & 45 & 3.7 & 1.7 & no snow & no snow & - \\
\hline
\end{tabular}

* Discriminant index $D_{i}=8.6 \times 10^{-3} \mathrm{ly} \mathrm{sec}^{-1}$ for $(H+L E) A$.

** Maximum observed snowfall to the lee of Lake Huron. 
(1972-73 and 1973-74), precluding the use of current data for a further analysis of the predictive index. Temperature surveys of Lake Huron were conducted during the 1969-70 snowfall season. Therefore, historical data were gathered as an independent data sample to test the results of the study period. The synoptic charts for the 1969-70 snowfall season were examined and several days were chosen from each month which did not violate the two limitations listed in Section 4. This resulted in an independent data sample of 24 days.

The average vertical flux of energy over Lake Huron was estimated and the occurrence or nonoccurrence of lake-effect snowfall was predicted for each of these 24 days. The predictions were then compared to the observed conditions as listed in the Monthly Records (Atmospheric Environment Service, 1969-70). These results are listed in Table 1. There were three incorrect predictions (a $12.5 \%$ error in classification), which was only slightly higher than the expected frequency of misclassification ( $9 \%$ ). The estimated vertical energy flux on two of the three days of incorrect prediction was slightly below the threshold value and within the area of overlap between the two populations, making an accurate prediction difficult to obtain. Although snowfall did occur on the third day of incorrect prediction (16 February), the maximum snowfall observed to the lee of Lake Huron $(0.15 \mathrm{~cm}$ water equivalent) was almost negligible. It is significant to note that the frequency of ice cover data reports was irregular during this independent test year, resulting in a probable source of error.

\section{Summary}

The occurrence of lake-effect snowfall for any given day can be predicted on the basis of the estimated mean vertical flux of energy from the lake measured by $\overline{\Delta Q}=(H+L E) A$. A threshold value of $\overline{\Delta Q}$ was calculated for the occurrence of lake-effect snowfall days. The probability of future misclassification using this discriminant index was calculated to be only $9 \%$. Further evidence was gained for the validity of the threshold value when the discriminant index was applied to an independent set of data.

While the Lake Huron basin was utilized for statistical purposes, the parameters are sufficiently generalized to allow the model to be applied to any mesoscale water body. Each of the Great Lakes, for example, differs in shape, size and orientation but all are somewhere near the mesoscale and all should force similar scale motions during lake-effect snowfall occurrences. The temperature surveys of Lake Huron began again this spring (1974) providing current data which should be analyzed using this discriminant index.

The emphasis in the forecast offices of the Great Lakes region is on the synoptic-scale motions with local experience being utilized for the forecasting of these smaller mesoscale systems. It would be a simple procedure to supplement the current forecasting method with the use of this index. It should be noted that on an operational basis, a reasonable estimate of $\overline{\Delta Q}$ could be obtained using the mean temperatures and streamlines for a given day. It is also conceivable that a nomogram could be developed utilizing the mean lake temperature in conjunction with the mean daily air temperatures and wind speeds at several upwind stations to obtain approximate but quick estimates of the probability of lake-effect occurrences. In addition to current and future data within the Great Lakes basin, the threshold value for occurrence remains to be applied to other research locations.

Acknowledgments. The author would like to express his appreciation to Prof. F. K. Hare for his guidance during the preparation of this manuscript.

\section{REFERENCES}

Atmospheric Environment Service, 1969-70 and 1971-72: Monthly Record of Meteorological Observations, Downsview, Ontario.

Eichenlaub, V. L., 1970: Lake-effect snowfall to the lee of the Great Lakes: Its role in Michigan. Bull. Amer. Meteor. Soc., 51, 403-412.

McVehil, G. E., C. W. C. Rodgers and E. J. Mack, 1969 : Investigation of measurement techniques for heat transfer and evaporation from the Great Lakes. Rept. VC-2666-P-4, Cornell Aeronautical Laboratory, 49 pp.

Phillips, D. W., 1972: Modification of surface air over Lake Ontario in winter. Mon. Wea. Rev., 100, 662-670 (also, M.Sc. thesis, University of Toronto, $1971,89 \mathrm{pp}$.).

Priestley, C. H. B., 1959: Turbulent Transfer in the Lower Atmosphere. The University of Chicago Press, $125 \mathrm{pp}$.

Richards, T. L., and V. S. Derco, 1963: The role of lake-effect storms in the distribution of snowfall in southern Ontario. Proc. 20ih Eastern Snow Conference, Atmospheric Environment Service, Toronto, 61-85.

- H. Dragert and D. R. McIntyre, 1966: Influence of atmospheric stability and overwater fetch on winds over the lower Great Lakes. Mon. Wea. Rev., 94, 448-453.

Sykes, R. B., 1966: The blizzard of '66 in central New York-a legend in its time. Weatherwise, 19, 241-247.

Wiggin, B. L., 1950: Great snows of the Great Lakes. Weatherwise, $3,123-126$. 